Article

\title{
Low-Salt Intake Suggestions in Hypertensive Patients Do not Jeopardize Urinary Iodine Excretion
}

\author{
Natale Musso *(D, Lucia Conte, Beatrice Carloni, Claudia Campana, Maria C. Chiusano \\ and Massimo Giusti \\ Centre for Secondary Hypertension, Unit of Clinical Endocrinology, Department of Internal Medicine, \\ University of Genoa Medical School, IRCCS Ospedale Policlinico San Martino, 16132 Genova, Italy; \\ luciaconte88@hotmail.it (L.C.); beatrice.carloni@gmail.com (B.C.); claudiadindon@hotmail.it (C.C.); \\ mcristinachiusano@libero.it (M.C.C.); magius@unige.it (M.G.) \\ * Correspondence: natale.musso@hsanmartino.it; Tel.: +39-010-5552087 (ext. 8793); Fax: +39-010-5556827
}

Received: 17 September 2018; Accepted: 17 October 2018; Published: 19 October 2018

\begin{abstract}
A low-sodium diet is an essential part of the treatment of hypertension. However, some concerns have been raised with regard to the possible reduction of iodine intake during salt restriction. We obtained 24-h urine collections for the evaluation of iodine (UIE) and sodium excretion $(\mathrm{UNaV})$ from 136 hypertensive patients, before and after $9 \pm 1$ weeks of a simple low-sodium diet. Body mass index (BMI), blood pressure (BP), and drug consumption (DDD) were recorded. Data are average \pm SEM. Age was $63.6 \pm 1.09$ year. BMI was $25.86 \pm 0.40 \mathrm{~kg} / \mathrm{m}^{2}$ before the diet and $25.38 \pm 0.37 \mathrm{~kg} / \mathrm{m}^{2}$ after the diet $(p<0.05)$. UNaV decreased from $150.3 \pm 4.01 \mathrm{mEq} / 24-\mathrm{h}$ to $122.8 \pm 3.92 \mathrm{mEq} / 24-\mathrm{h}(p<0.001)$; UIE decreased from $186.1 \pm 7.95 \mu \mathrm{g} / 24-\mathrm{h}$ to $175.0 \pm 7.74 \mu \mathrm{g} / 24-\mathrm{h}$ $(p=\mathrm{NS})$; both systolic and diastolic BP values decreased (by $6.15 \pm 1.32 \mathrm{mmHg}$ and by $3.75 \pm 0.84 \mathrm{mmHg}$, respectively, $p<0.001$ ); DDD decreased ( $\triangle$ DDD $0.29 \pm 0.06, p<0.05$ ). $\mathrm{UNaV}$ and UIE were related both before $(r=0.246, p=0.0040)$ and after the diet $(r=0.238$, $p=0.0050)$. UNaV and UIE were significantly associated both before and after the diet $(p<0.0001$ for both). After salt restriction UIE showed a non-significant decrease remaining in an adequate range. Our dietary suggestions were aimed at avoiding preserved foods, whereas the cautious use of table salt was permitted, an approach which seems safe in terms of iodine intake.
\end{abstract}

Keywords: blood pressure; dietary sodium; hypertension; iodine; salt

\section{Introduction}

A low-salt diet constitutes a standard approach to the treatment of hypertensive patients [1-4]. Salt is the fundamental source of dietary sodium, an excess of which is linked to hypertension and cardiovascular diseases [5-7]. While reducing excess dietary sodium is universally acknowledged to be a favorable step in the reduction of cardiovascular risk [1-4], the recommendation of a low-sodium approach in the general population is still controversial [8]. Recently, a J-shaped curve linking sodium intake to cardiovascular events has been proposed $[9,10]$, pointing to a possible risk induced by a decreased sodium intake in the general population. However, these data have been disputed [11].

In Italy iodine supplementation was first undertaken in 1921 and iodized salt was introduced by regulatory authorities in 1924 [12]. Since then, substantial progress has been made in the struggle against iodine deficiency [13]. Nevertheless a mild insufficiency persists [14] and only recently (Law n.55/2005) was a nationwide salt iodization program implemented [15].

The main concern raised by the reduction of sodium intake regards the possible deficiency of iodine intake during a low-sodium diet [16]. In hypertensive patients in whom iodine status (IS) has been evaluated by 24-h urinary iodine excretion (UIE) or by spot urine iodine concentration (UIC), 
or by anamnestic instruments such as 24-h dietary recalls or food frequency questionnaires (FFQ), no general consensus has emerged $[17,18]$. This may partly stem from the different methods employed, the greatest limitation being associated with anamnestic evaluation [19] and with the variability of spot urine measurements versus the gold standard of UIE [20,21]. Another issue concerns the general approach of studies in which sodium and iodine intake have been evaluated, in accordance with an observational protocol, whereby it is assumed that patients displaying a reduction in urinary sodium excretion are following a low-sodium diet, while those displaying no reduction are not $[22,23]$. Few intervention studies have shown adequate levels of iodine intake after salt restrictions [24,25].

An additional problem arises from the type of population examined. As a general rule, when an iodine-sufficient population is studied, patients on a low-sodium diet show reduced UIC/UIE, but no substantial change in IS [26]. When iodine-deficient patients follow a low-sodium diet, IS worsens [17,27].

In Italy, these concerns have already been raised [28]. Iodine deficiency leads to endemic goiter and cretinism, because iodine is essential for the synthesis of thyroid hormones. In our country public committees were appointed since the first half of the XIX century, for the identification of areas of endemic goiter and endemic cretinism, mostly in the north-western and insular areas [15]. Since then, many epidemiological evidences showed that iodine deficiency is present in mountain as well as in coastal regions [15]. Although our district, the Liguria Region, is situated in a country of mild iodine deficiency, it has recently become iodine-sufficient [29].

The aim of the present study was to evaluate the modification of UIE induced by a proposed low-sodium diet in hypertensive patients. Urinary iodine excretion and 24-h urinary sodium excretion $(\mathrm{UNaV})$ were measured by standard methods before and after the administration of a dietary protocol.

\section{Materials and Methods}

In a larger cohort of 291 hypertensive patients [30], we obtained a 24-h urine collection (above at least $700 \mathrm{~mL}$ ) from 157 patients for UIE and $\mathrm{UNaV}$ evaluation (basal value: time t0), together with BMI and blood pressure (BP) measurements. A low-sodium diet was then proposed. After $9 \pm 1$ weeks (mean \pm SD) we repeated the 24-h urine collection (time t2), BMI recording, and BP measurements.

The low-sodium diet prescribed by a dietitian was based on simple recommendations printed on a single A4 sheet of paper [30]. Patients were advised to avoid salty foods, ice-cream, cheese, and cured meats, such as bacon, ham, sausages, and so on. Low-sodium bottled water was recommended. The patients were also asked to switch from regular bread to salt-free bread, which is commonly available in Italy. Table salt itself was not banned, although limited use was suggested [30].

Twenty-four hour urines were collected in accordance with a standard protocol: after the first morning void (to be discarded) patients were requested to record the time and to collect every subsequent void until the same time the following day, when they had to collect the content of the last void. All patients received written and verbal instructions, together with the appropriate urine containers.

Blood pressure was measured by means of a semi-automated repeated-measures method (HEM 907 BP monitor, OMRON, Kyoto, Japan) as previously described [30] both at $\mathrm{t} 0$ and at $\mathrm{t} 2$. Blood pressure was measured three times at each visit and the last value (BP3) was considered for analysis. Body weight and $\mathrm{BMI}$ were obtained both at $\mathrm{t} 0$ and at $\mathrm{t} 2$. Anti-hypertensive drugs (as defined daily doses-DDD following the WHO definitions) [31] were recorded both at $\mathrm{t} 0$ and at $\mathrm{t} 2$. Halfway between the two visits, patients were suggested to have their BP evaluated by their general practitioner (who was aware of the study but blind to the results), which adjusted their drug treatment, if necessary [30].

$\mathrm{UNaV}$ was measured by an AutoAnalyzer (COBAS 8000 Roche/Hitachi with an ISE module; Roche Diagnostics, Indianapolis, IN, USA), while urinary iodine was measured by means of a current commercial colorimetric method (Celltech, Turin, Italy) all CVs are below 8\%.

All patients were on anti-hypertensive drug treatment. Patients on thyroid hormones, amiodarone or with a recent history of contrast-media exposure were excluded. Patients unable or unwilling to provide two ( $\mathrm{t} 0$ and $\mathrm{t} 2$ ) 24-h urine collections (i.e., those with less than $700 \mathrm{~mL}$ of urines 
and/or violation of void collection), or with concomitant diseases such as congestive heart failure, atrial fibrillation, renal failure, diabetes, electrolyte abnormalities, secondary hypertension, or goiter were deemed ineligible.

Finally, 136 patients, who had successfully provided 24-h urine collections twice in a two months period, were selected. Neither FFQ nor 24-h dietary recalls were used. The study population consisted of Caucasian Europeans, 98\%, and Latin Americans, 2\%. Of the 136 patients, 84 (61.76\%) claimed to use iodized table salt routinely, in agreement with our national data [15]. All subjects gave their informed consent for inclusion before they participated in the study. The study was conducted in accordance with the Declaration of Helsinki, and the protocol was approved by the Ethics Committee of our Hospital.

\section{Statistics}

Statistical analysis was performed using a commercial software package: PRISM 7.0 (Graph Pad Software, La Jolla, CA, USA). Paired Student's $t$-test, non-parametric analysis (Mann-Whitney, or $t$-test with Welch correction, followed by F-test to compare variances), repeated-measures ANOVA followed by multiple-comparison Newman-Keuls post-test, Kruskal-Wallis test (with Dunn's multiple comparison test), one-way ANOVA followed by Bartlett's test for equal variances, linear regression analysis, Fisher's exact test and Chi-square test were carried out. The significance cut-off was set at $p<0.05$.

\section{Results}

Data are reported throughout as average \pm SEM unless otherwise stated.

Patients were 83 females and 53 males. Their mean age was $63.6 \pm 1.09$ year.

Our intervention consisted of proposing a simple low-sodium protocol. The time-span between the administration of the dietary protocol (visit at time t0) and the final visit (time t2) was $9 \pm 0.12$ weeks:

- BMI was $25.86 \pm 0.40 \mathrm{~kg} / \mathrm{m}^{2}$ before the dietary suggestions (visit t0) and $25.38 \pm 0.37 \mathrm{~kg} / \mathrm{m}^{2}$ afterwards (visit t2) ( $t$-test and repeated-measures ANOVA and Newman-Keuls post-test, $p<0.05$ ).

- $\mathrm{UNaV}$ decreased from $150.3 \pm 4.01 \mathrm{mEq} / 24-\mathrm{h}$ at visit to to $122.8 \pm 3.92 \mathrm{mEq} / 24-\mathrm{h}$ at visit t2 (repeated-measures ANOVA and post-test, $p<0.001$ ).

- Both systolic and diastolic BP values decreased significantly from visit t0 to visit t2 (by $6.15 \pm 1.32 \mathrm{mmHg}$ and by $3.75 \pm 0.94 \mathrm{mmHg}$, respectively. ANOVA and post-test, $p<0.001$ ) (Figure 1).

- Drug consumption also decreased from visit t0 to visit t2 ( $\triangle \mathrm{DDD} 0.29 \pm 0.06, t$-test, $p<0.05$ ).

- Median UIE global values were $184.2 \mu \mathrm{g} / 24$-h (lower and upper 95\% CI 170.3 and 201.9) at t0, and $162.0 \mu \mathrm{g} / 24-\mathrm{h}$ (lower and upper $95 \%$ CI 159.6 and 190.3) at $\mathrm{t} 2$.

- Median UIE values in females were $178.2 \mu \mathrm{g} / 24$-h (lower and upper 95\% CI 163.0 and 204.3) at t0, and $153.7 \mu \mathrm{g} / 24-\mathrm{h}$ (lower and upper 95\% CI 151.3 and 188.5) at t2.

- Median UIE values in males were $188.0 \mu \mathrm{g} / 24$-h (lower and upper 95\% CI 164.9 and 215.2) at $\mathrm{t} 0$, and $170.0 \mu \mathrm{g} / 24$-h (lower and upper 95\% CI 155.9 and 210.5) at t2. One way ANOVA $(\mathrm{F}=0.6105, R$ square 0.006788$)$ showed non-significant differences between UIE values in males vs. females both before and after the diet period $(p=0.6087)$. Bartlett's test for equal variances gave non-significant results (Bartlett's statistics 1.449, $p=0.6940$, Newman-Keuls multiple comparison test $p>0.05)$.

- UIE was below $100 \mu \mathrm{g} / 24-\mathrm{h}$ in 28 patients before the suggested diet, and in 28 patients thereafter (Fisher's exact test: $p=\mathrm{NS}$; Chi-square, df: $0.0,1 ; p=\mathrm{NS}$ ).

- $\quad$ UIE decreased from $186.1 \pm 7.95 \mu \mathrm{g} / 24$-h at visit t0, to $175.0 \pm 7.74 \mu \mathrm{g} / 24$-h at visit t2 (repeated-measures ANOVA and post-test, $p=$ NS). Furthermore, these data were reanalyzed with non-parametric tests (Mann-Whitney, or Welch correction, $t=1.002, \mathrm{df}=269,95 \%$ C.I. -10.67 to +32.97 ), to avoid distributional assumptions (again, differences were non-significant: $p=0.2737$ to $p=0.3173$ ). A possible UIE variability induced by the dietary suggestions was challenged with an 
$\mathrm{F}$ test to compare variances before and after the observation period. $\mathrm{F}$ test showed non-significant differences (F, DFn, Dfd, 1057, 135, 135; $p=0.7484$ ).

- Significant relationships were found between $\mathrm{UNaV}$ and UI both before the administration of the protocol, at visit t0 $(r=0.246, p=0.004)$ (Figure 2$)$ and after, at visit t2 $(r=0.238, p=0.005)$ (Figure 3).

- $\mathrm{UNaV}$ and UIE were significantly associated both before and after the dietary suggestions (Chi-square test; df at t0 75.55, 1; df at t2 205.6, 1; $p<0.0001$ for both).

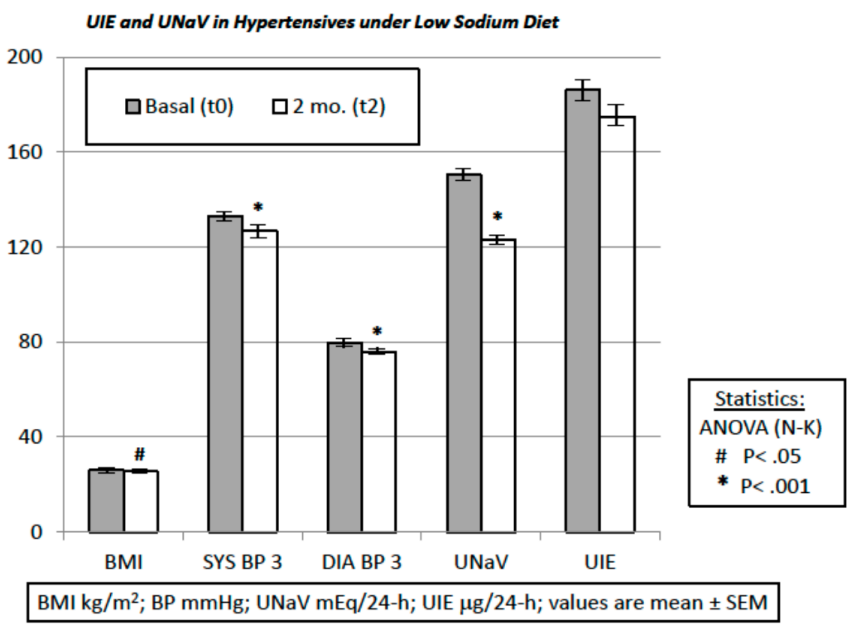

Figure 1. Main Data. $n=136$ pts, 83 females and 53 males. ANOVA followed by Newman-Keuls post-test for repeated measures. Data are reported as mean and SD.

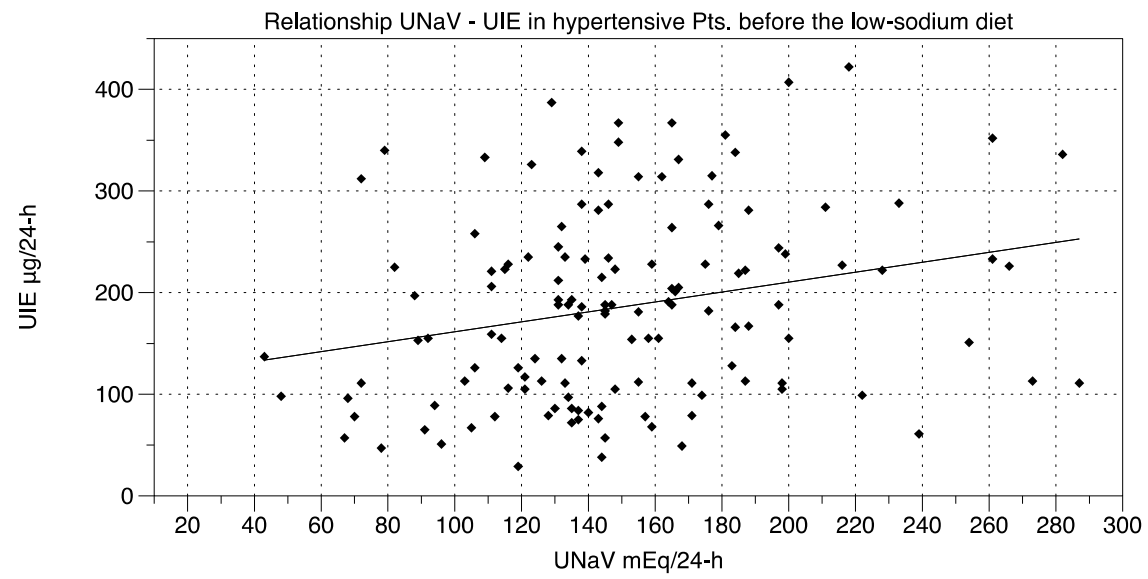

Figure 2. Relationship between $\mathrm{UNaV}(\mathrm{mEq} / 24-\mathrm{h})$ and UIE ( $\mu \mathrm{g} / 24-\mathrm{h})$ before the diet period (time t0). Statistics: $r=0.246 ; p=0.004$. 


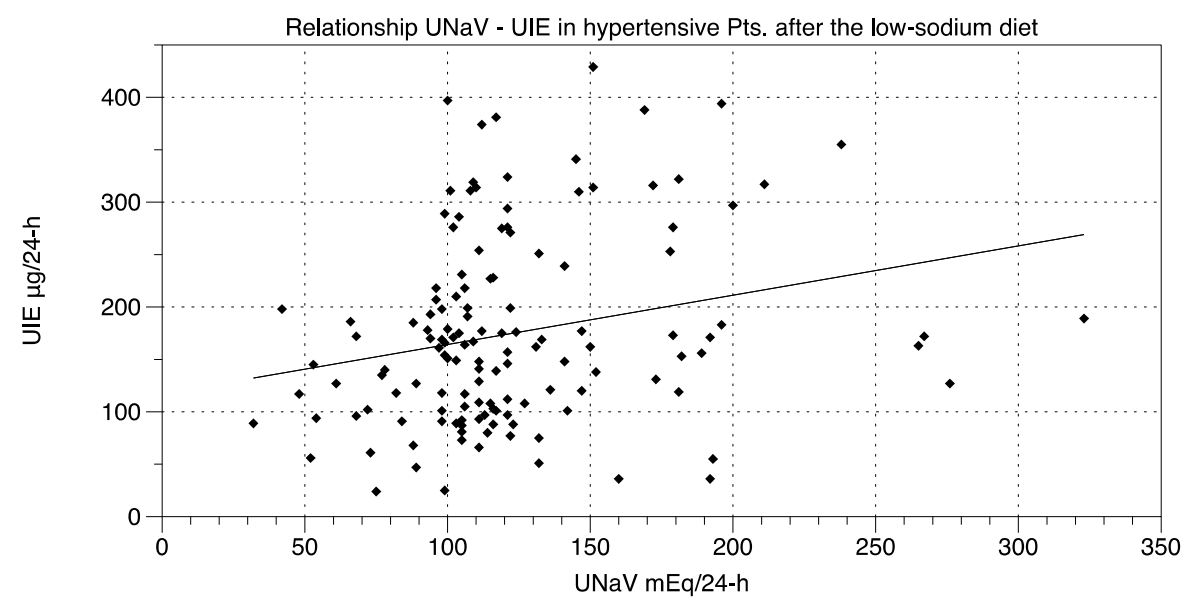

Figure 3. Relationship between $\mathrm{UNaV}(\mathrm{mEq} / 24-\mathrm{h})$ and UIE ( $\mu \mathrm{g} / 24-\mathrm{h})$ after the diet period (time $\mathrm{t} 2$ ). Statistics: $r=0.238 ; p=0.005$.

\section{Discussion}

The proposed low-sodium diet induced a significant reduction in UNaV, BMI, BP, and DDD in our patients. Urinary iodine excretion showed a small, non-significant decrease.

We did not monitor the actual diet in our patients, because of the inherent limits of FFQ and 24-h recall methods [19]. Instead, we relied on the $\mathrm{UNaV}$, which is usually considered the gold standard for the assessment of the sodium content of a diet [19]. Similarly, we relied on the UIE as a reference index of iodine intake [20,21].

In our patients we did not evaluate urinary creatinine excretion, which is of limited value as a measure of the completeness of 24-h collection [32,33], because of the high variability of creatinine in urine, with a reported SD as high as 29 to $79 \%$ of the mean [32,34], with sensitivity and specificity for identifying incomplete collections as low as $6 \%$ and $57 \%$, respectively [35]. Instead, we relied on the total 24-h urine volumes, with a high cut-off of $700 \mathrm{~mL}$ [30].

In our patients, the decrease in $\mathrm{UNaV}$ after the dietary suggestions was paralleled by significant improvements in BMI and BP values, with an additional significant decrease in drug consumption.

Our patients seemed to follow our suggestions, apparently reducing their sodium intake from $(150.3 \mathrm{mEq} \times 23=) 3.46 \mathrm{~g} /$ day, which is equivalent to $8.78 \mathrm{~g} /$ day of salt, to $(122.8 \mathrm{mEq} \times 23=) 2.82$ $\mathrm{g} /$ day, which is equivalent to $7.17 \mathrm{~g} /$ day of salt. This small but significant decrease, albeit lower than that suggested in the Guidelines [1-4], yielded a significant improvement in our patients' BP values (even more important in light of their reduced drug intake), once again displaying the favorable effect of a low-sodium approach to arterial pressure control.

This effective UNaV reduction did not appear to affect UIE, which showed a non-significant reduction from 186.1 to $175.0 \mu \mathrm{g} / 24-\mathrm{h}$. The approximate iodine intake thus decreased from $(186.1 / 0.92$ $=) 202.3 \mu \mathrm{g} /$ day, to $(175.0 / 0.92=) 190.2 \mu \mathrm{g} /$ day $[25,36]$.

The number of iodine-deficient patients (UIE below $100 \mu \mathrm{g} / 24-\mathrm{h}$ ) did not change from the basal observation to the final visit (28/136 to $28 / 136$, i.e., $20.59 \%)$.

Our data agree with previously published findings, which indicate that reducing sodium consumption in an iodine-sufficient population does not compromise iodine intake [26]. In our hypertensive patients, a successful intervention (in the form of dietary salt intake suggestions) was followed by favorable effects in terms of $\mathrm{UNaV}, \mathrm{BMI}$, and BP reduction (even with a reduction in the need for drugs).

Our instructions do not appear to induce a substantial nor significant decrease in iodine intake, and the number of iodine-deficient subjects did not change substantially, nor significantly (actually, it did not change at all). Differences between females and males were non-significant. 
In Italy, the primary source of salt is not processed or canned food (the use of which remains negligible), nor the amount of salt added at the table or during cooking; rather, it is constituted by three categories of food: bread, cheese, and cured meats [37]. The aim of our dietary suggestions was to reduce sodium intake, while minimizing the iodine decrease. On our market, sales of iodized table salt have risen to a current level of the $60 \%$ [15]. Although our district, the Liguria Region, has recently achieved iodine sufficiency, Italy (as noted in the Introduction) suffers from mild iodine deficiency [29]. This situation is reflected in our data, which showed average iodine sufficiency (average UIE $186.1 \mu \mathrm{g} / 24$-h, median UIE $184.2 \mu \mathrm{g} / 24$-h; lower and upper 95\% CI 170.3 and 201.9 before the dietary suggestions), but with $20 \%$ of iodine-deficient subjects (UIE $<100 \mu \mathrm{g} / 24$-h). Efforts to reduce salt intake in our country must take this fragile IS into account. This is why our suggestions were aimed at reducing the main sources of salt (bread, cheese, and cured meats), whereas table salt was not banned; we therefore managed not to cut a possible main source of iodine.

The fact that UNaV and UIE were significantly related and associated, both before and after the administration of the diet protocol, suggests a possible common source of both sodium and iodine; given that the three salty foods had been excluded from the dietary protocol, this common source was presumably table salt. Our results support this view: the non-significant decrease in UIE seen in our patients seems to fit in with the current low use of iodized salt (3-8\%) by the Italian food industry [28], with the implication that table salt remains the main source of iodine in our country [28].

\section{Conclusions}

In an area of iodine sufficiency, albeit in a mild iodine-deficient country, where table salt is the main source of iodine, a low-sodium approach which primarily limits the salty foods (instead of a "no salt added" suggestion) seems safe in terms of iodine intake, and does not worsen the IS.

Author Contributions: Conceptualization: M.G. and N.M.; Methodology: N.M., B.C., M.C.C.; Investigation and Data Curation: N.M., B.C., C.C., M.C.C.; Formal Analysis and Writing-Original Draft Preparation: N.M., L.C., M.G.; Writing-Review and Editing: N.M.; Supervision: M.G.

Funding: This research received no external funding.

Conflicts of Interest: The authors declare no conflict of interest.

\section{References}

1. James, P.A.; Oparil, S.; Carter, B.L.; Cushman, W.C.; Dennison-Himmelfarb, C.; Handler, J.; Lackland, D.T.; LeFevre, M.L.; MacKenzie, T.D.; Ogedegbe, O.; et al. 2014 Evidence-Based Guideline for the Management of High Blood Pressure in Adults: Report From the Panel Members Appointed to the Eighth Joint National Committee (JNC 8). JAMA 2014, 311, 507-520. [CrossRef] [PubMed]

2. Van Horn, L.; Carson, J.A.S.; Appel, L.J.; Burke, L.E.; Economos, C.; Karmally, W.; Lancaster, K.; Lichtenstein, A.H.; Johnson, R.K.; Thomas, R.J.; et al. Recommended dietary pattern to achieve adherence to the American Heart Association/American College of Cardiology (AHA/ACC) Guidelines: A scientific statement from the American Heart Association. Circulation 2016, 134, e505-e529. [CrossRef] [PubMed]

3. Whelton, P.K.; Carey, R.M.; Aronow, W.S.; Casey, D.E., Jr.; Collins, K.J.; Dennison Himmelfarb, C.; DePalma, S.M.; Gidding, S.; Jamerson, K.A.; Jones, D.W.; et al. 2017 ACC/AHA/AAPA/ ABC/ACPM/AGS/APhA/ASH/ASPC/NMA/PCNA Guideline for the Prevention, Detection, Evaluation, and Management of High Blood Pressure in Adults. Hypertension 2018. [CrossRef]

4. Williams, B.; Mancia, G.; Spiering, W.; Agabiti Rosei, E.; Azizi, M.; Burnier, M.; Clement, D.L.; Coca, A.; de Simone, G.; Dominiczak, A.; et al. 2018 ESC/ESH Guidelines for the management of arterial hypertension. Eur. Heart J. 2018, 39, 3021-3104. [CrossRef] [PubMed]

5. Strazzullo, P.; D'Elia, L.; Kandala, N.B.; Cappuccio, F.P. Salt intake, stroke, and cardiovascular disease: Meta-analysis of prospective studies. BMJ 2009, 339, b4567. [CrossRef] [PubMed]

6. He, F.J.; MacGregor, G.A. Salt reduction lowers cardiovascular risk: Meta-analysis of outcome trials. Lancet 2011, 378, 380-382. [CrossRef] 
7. Taylor, R.S.; Ashton, K.E.; Moxham, T.; Hooper, L.; Ebrahim, S. Reduced dietary salt for the prevention of cardiovascular disease: A meta-analysis of randomized controlled trials (Cochrane review). Am. J. Hypertens. 2011, 24, 843-853. [CrossRef] [PubMed]

8. Bram, B.; Huang, X.; Cupples, W.A.; Hamza, S.M. Understanding the two faces of low-salt intake. Curr. Hypertens. Rep. 2017, 19, 49. [CrossRef] [PubMed]

9. Graudal, N.; Jurgens, G.; Baslund, B.; Alderman, M.H. Compared with usual sodium intake, low- and excessive-sodium diets are associated with increased mortality: A meta-analysis. Am. J. Hypertens. 2014, 27, 1129-1137. [CrossRef] [PubMed]

10. O'Donnell, M.; Mente, A.; Rangarajan, S.; McQueen, M.J.; Wang, X.; Liu, L.; Yan, H.; Lee, S.F.; Mony, P.; Devanath, A.; et al. Urinary sodium and potassium excretion, mortality, and cardiovascular events. N. Engl. J. Med. 2014, 371, 612-623. [CrossRef] [PubMed]

11. Oparil, S. Low sodium intake-Cardiovascular health benefit or risk? N. Engl. J. Med. 2014, 371, 677-679. [CrossRef] [PubMed]

12. Kimball, O.P. Endemic goiter and public health. Am. J. Public Health Nations Health 1928, 18, 587-601. [CrossRef] [PubMed]

13. Bath, S.C. The challenges of harmonising the iodine supply across Europe. Lancet Diabetes Endocrinol. 2017, 5, 411-412. [CrossRef]

14. Lazarus, J.H. Iodine status in Europe in 2014. Eur. Thyroid J. 2014, 3, 3-6. [CrossRef] [PubMed]

15. Olivieri, A.; Di Cosmo, C.; De Angelis, S.; Da Cas, R.; Stacchini, P.; Pastorelli, A.; Vitti, P. Regional Observatory for Goiter Prevention. The way forward in Italy for iodine. Minerva Med. 2017, 108, 159-168. [PubMed]

16. World Health Organization. Salt Reduction and Iodine Fortification Strategies in Public Health; World Health Organization: Geneva, Switzerland, 2014.

17. Tayie, F.A.; Jourdan, K. Hypertension, dietary salt restriction and iodine deficiency among adults. Am. J. Hypertens. 2010, 23, 1095-1102. [CrossRef] [PubMed]

18. Pearce, E.N.; Andersson, M.; Zimmermann, M.B. Global iodine nutrition: Where do we stand in 2013? Thyroid 2013, 23, 523-528. [CrossRef] [PubMed]

19. McLean, R.M.; Farmer, V.L.; Nettleton, A.; Cameron, C.M.; Cook, N.R.; Campbell, N.R.C.; TRUE Consortium. Assessment of dietary sodium intake using food frequency questionnaires and 24-hour urinary sodium excretion: A systematic literature review. J. Clin. Hypertens. 2017, 19, 1214-1230. [CrossRef] [PubMed]

20. Ji, C.; Lu, T.; Dary, O.; Legetic, B.; Campbell, N.R.; Cappuccio, F.P. Systematic review of studies evaluating urinary iodine concentration as a predictor of 24 hour urinary iodine excretion for estimating population iodine intake. Rev. Panam. Salud Publica 2015, 38, 73-81. [PubMed]

21. Conkle, J.; van der Haar, F. The use and interpretation of sodium concentrations in casual (spot) urine collections for population surveillance and partitioning of dietary iodine intake sources. Nutrients 2017, 9, 7. [CrossRef] [PubMed]

22. Charlton, K.E.; Jooste, P.L.; Steyn, K.; Levitt, N.S.; Ghosh, A. A lowered salt intake does not compromise iodine status in Capetown, South Africa, where salt iodization is mandatory. Nutrition 2013, 29, 630-634. [CrossRef] [PubMed]

23. Ahn, J.; Lee, J.H.; Lee, J.; Baek, J.Y.; Song, E.; Oh, H.S.; Kim, M.; Park, S.; Jeon, M.J.; Kim, T.Y.; et al. Association between urinary sodium levels and iodine status in Korea. Korean J. Int. Med. 2018. [CrossRef] [PubMed]

24. Simpson, F.O.; Thaler, B.I.; Paulin, J.M.; Phelan, E.L.; Cooper, G.J. Iodide excretion in a salt-restriction trial. N. Z. Med. J. 1984, 97, 890-893. [PubMed]

25. He, F.J.; Ma, Y.; Feng, X.; Zhang, W.; Lin, L.; Guo, X.; Zhang, J.; Niu, W.; Wu, Y.; MacGregor, G.A. Effect of salt reduction on iodine status assessed by 24 hour urinary iodine excretion in children and their families in northern China: A substudy of a cluster randomised controlled trial. BMJ Open 2016, 6, e011168. [CrossRef] [PubMed]

26. Vega-Vega, O.; Fonseca-Correa, J.I.; Mendoza-De la Garza, A.; Rincon-Pedrero, R.; Espinosa-Cuevas, A.; Baeza-Arias, Y.; Dary, O.; Herrero-Bervera, B.; Nieves-Anaya, I.; Correa-Rotter, R. Contemporary dietary intake: Too much sodium, not enough potassium, yet sufficient iodine: The SALMEX Cohort study. Nutrients 2018, 10, 816. [CrossRef] [PubMed]

27. Charlton, K.; Ware, L.J.; Baumgartner, J.; Cockeran, M.; Schutte, A.E.; Naidoo, N.; Kowal, P. How will South Africa's mandatory salt reduction policy affect its salt iodisation programme? A cross-sectional analysis from the WHO-SAGE Wave 2 Salt \& Tobacco study. BMJ Open 2018, 8, e020404. [PubMed] 
28. Pastorelli, A.A.; Stacchini, P.; Olivieri, A. Daily iodine intake and the impact of salt reduction on iodine prophylaxis in the Italian population. Eur. J. Clin. Nutr. 2015, 69, 211-215. [CrossRef] [PubMed]

29. Monitoring of the Nationwide Program of Iodine Prophylaxis in Italy. Available online: http:/ / old.iss.it/ binary/publ/cont/14_6_web.pdf (accessed on 15 August 2018).

30. Musso, N.; Carloni, B.; Chiusano, M.C.; Giusti, M. Simple dietary advice reduces 24-hour urinary sodium excretion, blood pressure, and drug consumption in hypertensive patients. J. Am. Soc. Hypertens. 2018, 12, 652-659. [CrossRef] [PubMed]

31. WHO Collaborating Centre for Drug Statistics Methodology. Guidelines for ATC Classification and DDD Assignment; Norwegian Institute of Public Health: Oslo, Norway, 2017.

32. Greenblatt, D.J.; Ransil, B.J.; Harmatz, J.S.; Smith, T.W.; Duhme, D.W.; Koch-Weser, J. Variability of 24-hour urinary creatinine excretion by normal subjects. J. Clin. Pharmacol. 1976, 16, 321-328. [CrossRef] [PubMed]

33. Sawant, P.D.; Kumar, S.A.; Wankhede, S.; Rao, D.D. Creatinine as a normalization factor to estimate the representativeness of urine sample. Intra-subject and inter-subject variability studies. Appl. Radiat. Isot. 2018, 136, 121-126. [CrossRef] [PubMed]

34. Murakami, K.; Sasaki, S.; Takahashi, Y.; Uenishi, K.; Watanabe, T.; Kohri, T.; Yamasaki, M.; Watanabe, R.; Baba, K.; Shibata, K.; et al. Sensitivity and specificity of published strategies using urinary creatinine to identify incomplete 24-h urine collection. Nutrition 2008, 24, 16-22. [CrossRef] [PubMed]

35. John, K.A.; Cogswell, M.E.; Campbell, N.R.; Nowson, C.A.; Legetic, B.; Hennis, A.J.M.; Patel, S.M. Accuracy and usefulness of select methods for assessing complete collection of 24-hour urine: A systematic review. J. Clin. Hypertens. 2016, 18, 456-467. [CrossRef] [PubMed]

36. Nath, S.K.; Moinier, B.; Thuillier, F.; Rongier, M.; Desjeux, J.F. Urinary excretion of iodide and fluoride from supplemented food grade salt. Int. J. Vitam. Nutr. Res. 1992, 62, 66-72. [PubMed]

37. WHO-Salt Reduction. Available online: https://www.who.int/news-room/fact-sheets/detail/saltreduction (accessed on 15 August 2018).

(C) 2018 by the authors. Licensee MDPI, Basel, Switzerland. This article is an open access article distributed under the terms and conditions of the Creative Commons Attribution (CC BY) license (http://creativecommons.org/licenses/by/4.0/). 